\title{
Treatment of Peyronie's disease via preoperative intralesional collagenase clostridium histolyticum followed by placement of an inflatable penile prosthesis: the new standard of care?
}

\author{
Jason Akerman ${ }^{1}$, Jason R. Kovac ${ }^{2}$ \\ ${ }^{1}$ Department of Urology, McMaster University, Hamilton, Ontario, Canada; ${ }^{2}$ Men's Health Center, Indianapolis, Indiana 46260, USA \\ Correspondence to: Dr. Jason R. Kovac, MD, PhD, FACS, FRCSC. Men's Health Center, 8240 Naab Road, Suite 220, Indianapolis, Indiana 46260, \\ USA. Email: jkovac@urologyin.com. \\ Comment on: Raheem OA, Hsieh TC. Penile prosthetic surgery for the management of Peyronie's disease. Transl Androl Urol 2017;6:S815-21.
}

Submitted Nov 07, 2017. Accepted for publication Nov 07, 2017.

doi: $10.21037 /$ tau.2017.11.04

View this article at: http://dx.doi.org/10.21037/tau.2017.11.04

Penile prosthetic surgery via insertion of an inflatable penile prosthesis (IPP) is well established as the gold standard for patients with Peyronie's disease and concurrent, severe erectile dysfunction (ED). For these patients, correction of curvature, erectile strength, and penile shortening have a significant impact on overall satisfaction and quality of life $(1,2)$.

In previous research on the use prosthetic penile surgery in men with Peyronie's disease, evidence exists to suggest that these patients should be limited to primarily "girthonly" models such as the AMS CX700 and Coloplast Titan (3). This treatment paradigm was initially based upon data by Montague et al. (4) obtained in the early 1990's. In that study, the authors compared outcomes in Peyronie's disease patients who received a girth-enhancing IPP (AMS CX700) to those who received a girth and lengtheningenhancing IPP (AMS Ultrex/LGX). The Ultrex group gained an average of $1.8 \mathrm{~cm}$ in penile length but were also more likely to have residual curvatures and require additional corporoplasties and repair (4). Those men with the more rigid, girth-enhancing prostheses produced improved outcomes in hardness with decreased residual curvatures (4). Unfortunately, this was at a cost of potential penile length—a major concern for many men with ED and Peyronie's disease. As such, no optimal treatment exists for men wishing both girth and length expansion in presence of severe ED requiring placement of an IPP.

Recent advances in the non-surgical management of Peyronie's disease offer a means to optimize men prior to prosthetic surgery to maximize penile length. It is tempting to speculate that by reducing pre-operative curvature, patients may conceivably achieve improved curvature resolution along with enhanced results gained through placement of a girth and length-enhancing prosthesis. Intra-lesional injection therapy with collagenase clostridium histolyticum $(\mathrm{CCH})$ has produced significant reductions in penile curvature and patient bother in phase $2 \mathrm{~b}$ and phase 3 clinical trials $(5,6)$. Furthermore, there is emerging evidence in the form of small case series which suggest that surgical intervention post- $\mathrm{CCH}$ treatment is both safe and effective.

When considering men with residual curvature post $\mathrm{CCH}$ intra-lesional therapy, Levine et al. (7) reported on seven men who underwent tunica-albuginea plication (TAP) or partial plaque excision and grafting (PEG). All seven men achieved functional straightness without any anatomical difficulties or surgical complications despite prior $\mathrm{CCH}$ treatment (7). Insertion of an IPP post-CCH has also been reported. In their retrospective series, Hellstrom et al. (8) studied 10 men who underwent surgical intervention for persistent curvature via penile plication, plaque incision/grafting, or placement of an IPP. Increased fibrosis was noted in the operative reports of three patients; however this finding did not negatively affect outcomes overall (8).

Specifically, with regards to the IPP, a total of three patients underwent IPP insertion post-CCH injection. Mean pre- and post-operative curvatures were $58^{\circ}$ and $15^{\circ}$ 
respectively - a very substantial improvement. While the type of implant used was not specified, this early reports confirms the safety of surgery post-CCH (8). Together, these two small case series suggest that men with residual curvature post-CCH can achieve favorable results with surgery, including IPP insertion.

Optimum timing of IPP insertion post-CCH treatment has yet to be determined. Mean time from final $\mathrm{CCH}$ injection to surgical intervention was 150.9 days ( $\sim 5$ months) in the Hellstrom (8) series and 182 days ( $\sim 6$ months) in the Levine series (7). It is interesting to note that in two of the three cases with increased fibrosis in the Hellstrom series, all were done $<100$ days from the last $\mathrm{CCH}$ injection. Based on these findings alone, a wait time of $>6$ months post-CCH was proposed (8).

For patients with ED and Peyronie's disease who are particularly troubled by the prospect of a reduction in penile length, pre-operative optimization with a full $\mathrm{CCH}$ course may increase their chances of successful use of a lengthening-type IPP. This would allow prosthetic surgeons to better address a substantial concern in Peyronie's disease patients and potentially improve overall operative satisfaction for these men.

\section{Acknowledgements}

None.

\section{Footnote}

Conflicts of Interest: The authors have no conflicts of interest to declare.

Cite this article as: Akerman J, Kovac JR. Treatment of Peyronie's disease via preoperative intralesional collagenase clostridium histolyticum followed by placement of an inflatable penile prosthesis: the new standard of care? Transl Androl Urol 2017;6(Suppl 5):S822-S823. doi: 10.21037/tau.2017.11.04

\section{References}

1. Smith JF, Walsh TJ, Conti SJ, et al. Risk factors for emotional and relationship problems in Peyronie's disease. J Sex Med 2008;5:1985-90.

2. Serefoglu EC, Smith TM, Kaufman GJ, et al. Factors associated with erectile dysfuntion and the Peyronie's disease questionnaire in patients with Peyronie's disease. Urology 2017;107:155-60.

3. Raheem OA, Hsieh TC. Penile prosthetic surgery for the management of Peyronie's disease. Trans Androl Urol 2017;6:S815-21.

4. Montague DK, Angermeier KW, Lakin MM, et al. AMS 3-piece inflatable penile prosthesis implantation in men with Peyronie's disease: comparison of CX and Ultrex cylinders. J Urol 1996;156:1633-5.

5. Gelbard M, Lipshultz LI, Tursi J, et al. Phase 2b study of clinical efficacy and safety of collagenase clostridium histolyticum in patients with Peyronie disease. J Urol 2012;187:2268-74.

6. Gelbard M, Goldstein I, Hellstrom WJ, et al. Clinical efficacy, safety, and tolerability of collagenase clostridium histolyticum for the treatment of Peyronie disease in 2 large double-blind, randomized, placebo controlled phase 3 studies. J Urol 2013;190:199-207.

7. Levine LA, Larsen SM. Surgical correction of persistent Peyronie's disease following collagenase clostridium histolyticum treatment. J Sex Med 2015;12:259-64.

8. DeLay K, Diao L, Nguyen HMT, et al. Successful treatment of residual curvature in Peyronie disease in men previously treated with intralesional collagenase clostridium histolyticum. Urology 2017. [Epub ahead of print]. 